\title{
Preoperative heat shock protein 47 levels identify colorectal cancer patients with lymph node metastasis and poor prognosis
}

\author{
KOICHIRO MORI, YUJI TOIYAMA, YOSHINAGA OKUGAWA, TAKASHI ICHIKAWA, YUKA NAGANO, \\ SATOSHI OKI, TADANOBU SHIMURA, HIROYUKI FUJIKAWA, JUNICHIRO HIRO, MINAKO KOBAYASH, \\ TOSHIMITSU ARAKI, YASUHIRO INOUE, YASUHIKO MOHRI and MASATO KUSUNOKI
}

Department of Gastrointestinal and Pediatric Surgery, Mie University Graduate School of Medicine, Tsu, Mie 514-8507, Japan

Received September 24, 2019; Accepted May 28, 2020

DOI: $10.3892 / 01.2020 .12196$

\begin{abstract}
Accumulating evidence suggests that overexpression of heat shock protein 47 (HSP47) increases cancer progression, and that HSP47 level in the tumor-associated stroma may serve as a diagnostic marker in various cancers. The present study aimed to evaluate whether HSP47 gene expression in colorectal cancer (CRC) tissues could be used to identify lymph node (LN) metastasis status preoperatively in patients with CRC. To do so, HSP47 gene expression was determined and its association with the clinicopathological characteristics of patients with CRC was analyzed. A total of 139 surgical specimens from patients with CRC and 36 patients with benign colonic disease undergoing surgery at Mie University Hospital were analyzed. HSP47 gene expression was determined by reverse transcription quantitative PCR using Power SYBR Green PCR methods. Expression level of HSP47 was significantly higher in CRC tissues compared with normal tissue from patients with benign colonic disease. Furthermore, high HSP47 expression was significantly associated with tumor progression, including high T stage, lymph node metastasis and venous invasion, and high TNM stage. High HSP47 expression may therefore serve as a novel predictive biomarker for determining patients with CRC and LN metastasis. According to Kaplan-Meier analysis, patients with high HSP47 expression level had significantly poorer overall survival than those with low HSP47 expression level. Furthermore, multivariate analyses identified HSP47 expression as an independent predictive marker for $\mathrm{LN}$
\end{abstract}

Correspondence to: Dr Yuji Toiyama, Department of Gastrointestinal and Pediatric Surgery, Mie University Graduate School of Medicine, 2-174 Edobashi, Tsu, Mie 514-8507, Japan

E-mail: ytoi0725@clin.medic.mie-u.ac.jp

Abbreviations: CRC, colorectal cancer; CT, computed tomography; EUS, endorectal ultrasonography; HSP47, heat shock protein 47; LN, lymph nodes; MRI, magnetic resonance imaging; OS, overall survival; PET/CT, positron emission tomography/CT; ROC, Receiver operating characteristic; TNM, tumor node metastasis

Key words: heat shock protein 47, gene expression, lymph node metastasis, colorectal cancer, biomarker metastasis and poor overall survival in patients with CRC. In summary, the present study demonstrated that HSP47 expression may be considered as a novel biomarker for predicting $\mathrm{LN}$ metastasis status and prognosis in patients with CRC.

\section{Introduction}

Colorectal cancer (CRC) is the third most common non-cutaneouscarcinomaand the third leading cause of cancer-associated mortality worldwide (1). The Tumor-Node-Metastasis (TNM) staging system established by the American Joint Committee on Cancer is widely used to predict prognosis and provide the most pertinent and effective treatment strategies in patients with CRC (2). According to the TNM staging system, the presence of positive lymph nodes (LN) determines the need for adjuvant chemotherapy in patients with colon cancer (3) and is associated with increased use of adjuvant radiation and chemotherapy in patients with rectal cancer (4). Although the 5-year-survival rate of patients with CRC and $\mathrm{LN}$ metastasis is only $69.2 \%$ (5), preoperative diagnosis of $\mathrm{LN}$ metastasis absence makes endoscopic mucosal resection or minimum bowel resection some possible options for patients with CRC. The development of tools for the accurate preoperative detection of LN metastasis might therefore serve an important role in optimizing the management of patients with CRC, such as minimizing surgery and evaluating the need for neoadjuvant chemotherapy and/or intensive adjuvant chemotherapy.

Non-invasive imaging modalities, including computed tomography (CT), magnetic resonance imaging (MRI), endorectal ultrasonography (EUS) and positron emission tomography/CT (PET/CT), are currently used for the preoperative diagnosis of LN metastasis in patients with CRC. However, these imaging modalities are unreliable, with relatively poor accuracy $(22-73,39-95,62-83$ and $63 \%$ for CT, MRI, EUS and PET/CT, respectively) (6,7).

The identification of predictive biomarkers of LN metastasis in CRC has mainly focused on the determination of the expression of several proteins by immunohistochemistry, of gene expression level (Carcinoembryonic antigen-related cell adhesion molecule 5 or Kallikrein- 6 mRNAs and FER1 like member 4 non-coding RNAs) or DNA methylation in colorectal tissues (8-11). A previous study from our laboratory performed a comprehensive analysis using a proteomics approach and 
selected candidate proteins that might be used to identify LN metastasis in CRC. The expression level of HSP47 in CRC and the number of HSP47-positive spindle-shaped stroma cells in CRC stroma evaluated by immunohistochemistry were significantly associated with LN metastasis, and the number of HSP47-positive spindle-shaped stroma cells was identified as a novel predictive biomarker for $\mathrm{LN}$ metastasis and poor prognosis in patients with CRC (12). However, immunohistochemical analysis depends on tissue processing and staining conditions, properties of the immunohistochemical reagents, including antibodies, and visualization system. In addition, it is difficult to evaluate expression level objectively and/or quantitatively as required for clinical biomarkers. Furthermore, immunohistochemical analysis using formalin-fixed, paraffin-embedded samples from resected CRC tissues cannot be used to identify LN metastasis status preoperatively.

The present study aimed to evaluate whether HSP47 gene expression level could be used in CRC tissues to identify LN metastasis status preoperatively. To do so, HSP47 gene expression level was quantified by reverse transcription quantitative (RT-q)PCR in frozen CRC and control samples from surgical specimens and the association between HSP47 gene expression and clinicopathological characteristics of patients with CRC was analyzed.

\section{Materials and methods}

Patients and sample collection. Patients with primary CRC who underwent surgical resection at Mie University Medical Hospital, Japan between January 2000 and January 2005 were enrolled in the present study. Mean age of the patients was 69 years and mean tumor size was $40 \mathrm{~mm}$. Patients with preoperative treatment, incomplete clinical data, inadequate follow-up or inadequate tissue samples were excluded. Patients with inflammatory bowel disease, familial adenomatous polyposis, hereditary non-polyposis colon cancer or other rare and complex types of tumors were also excluded from the present study. All tissue samples were collected from surgically resected specimens and were immediately frozen in liquid nitrogen and kept at $-80^{\circ} \mathrm{C}$ until RNA extraction. A total of 175 surgical samples, comprising 36 normal mucosa samples from patients with benign colonic disease and 139 cancer tissue samples from patients with CRC were analyzed. The clinicopathological characteristics of patients with CRC were based on TNM classification using the American Joint Committee on Cancer (2). This cohort comprised 79 men and 60 women (average age, 67.7 years), of whom 33, 44, 33 and 29 patients had stages I, II, III and IV CRC, respectively. The median follow-up time was 32.9 months (range, 0.4-115 months). The 5 -year survival rate was $80.1 \%$. No patient received chemotherapy or radiotherapy before surgery and no perioperative mortality was observed. The research protocol was approved by Mie University Hospital Ethical Review Committee. All participants provided written informed consent and agreed to donate their clinical specimens for research purposes.

$R N A$ extraction and $R T-q P C R$. Surgical specimens $(200 \mu \mathrm{g})$ were homogenized using a Mixer Mill MM 300 homogenizer (Qiagen Sciences, Inc.) and total RNA was isolated using the RNeasy Mini Kit (Qiagen, Inc.) according to the manufacturers' instructions. cDNA was synthesized using random hexamers and Superscript III reverse transcriptase (Invitrogen, Carlsbad, CA, USA) according to the manufacturers' protocol.

HSP47 expression level was determined by RT-qPCR using Power SYBR Green PCR Master Mix (Applied Biosystems; Thermo Fisher Scientific, Inc.) and a Step One Plus Real-Time PCR system (Applied Biosystems; Thermo Fisher Scientific, Inc.). The sequences of the primers were as follows: HSP47, forward 5'-ATGCAGAAGAAGGCTGTTGC-3', reverse 5'-GGCCTTGTTCTTGTCAATGG-3'; and $\beta$-actin, forward 5'-ACAGAGCCTCGCCTTTGC-3' and reverse 5'-GCGGCG ATATCATCATCC-3'. The amplification conditions were as follows: $95^{\circ} \mathrm{C}$ for $10 \mathrm{~min}, 40$ cycles of $95^{\circ} \mathrm{C}$ for $15 \mathrm{sec}$, and $60^{\circ} \mathrm{C}$ for $1 \mathrm{~min}$. After amplification, the products were subjected to an increasing temperature gradient from $60^{\circ} \mathrm{C}$ to $95^{\circ} \mathrm{C}$ at a rate of $0.3^{\circ} \mathrm{C} / \mathrm{sec}$ with continuous fluorescence monitoring, to produce a melting curve. The HSP47 expression level in each sample was normalized to $\beta$-actin expression level using the $2^{-\Delta \Delta \mathrm{Ct}}$ method (13).

Statistical analysis. All statistical analyses were performed using JMP version 10 (SAS Institute, Inc.). The results were expressed as the median values or as the mean \pm standard deviation. Comparisons were made using non-parametric Mann-Whitney U-tests for continuous variables. Differences between groups were estimated using Pearson's $\chi^{2}$ or Kruskal-Wallis tests. Dunn's tests were used as a method for multiple comparisons following Kruskal-Wallis test. Receiver operating characteristic (ROC) curves were established to determine cut-off expression values for predicting LN metastasis and prognosis using Youden's index. The Kaplan-Meier method was used to determine the cumulative probability of overall survival (OS) with Stage I-IV and disease-free survival (DFS) with Stage I-III patients with CRC, and differences were evaluated using log-rank tests. Prognostic factors were examined by univariate and multivariate analyses (Cox proportional hazards regression model). Logistic regression analysis was used to evaluate the factors influencing $\mathrm{LN}$ metastasis. $\mathrm{P}<0.05$ was considered to indicate a statistically significant difference.

\section{Results}

Differential gene expression patterns of HSP47 in normal colonic mucosa and CRC tissues. HSP47 expression level was significantly higher in CRC tissues $(n=139)$ compared with normal colonic mucosa $(n=36 ; P=0.0201$; Fig. 1A), and significantly higher in CRC with LN metastasis compared with CRC without $\mathrm{LN}$ metastasis ( $\mathrm{P}=0.0470$; Fig. 1A). In addition, HSP47 expression level was significantly higher in stage IV CRC tissues compared with stage I CRC tissues ( $\mathrm{P}=0.0186$; Fig. 1B).

Association between HSP47 expression level and clinicopathological characteristics in CRC. The associations between HSP47 expression level and various clinicopathological characteristics in patients with CRC were evaluated after dividing the 139 CRC cases into two groups, based on HSP47 expression level (high vs. low; Table I). The high/low cut-off values were determined by ROC analysis for $\mathrm{LN}$ metastasis (cut-off 0.0969762). Of the 139 CRC samples, 49.6\% (69/139) cases had high HSP47 expression $(>0.0969762)$ and $50.4 \%$ 

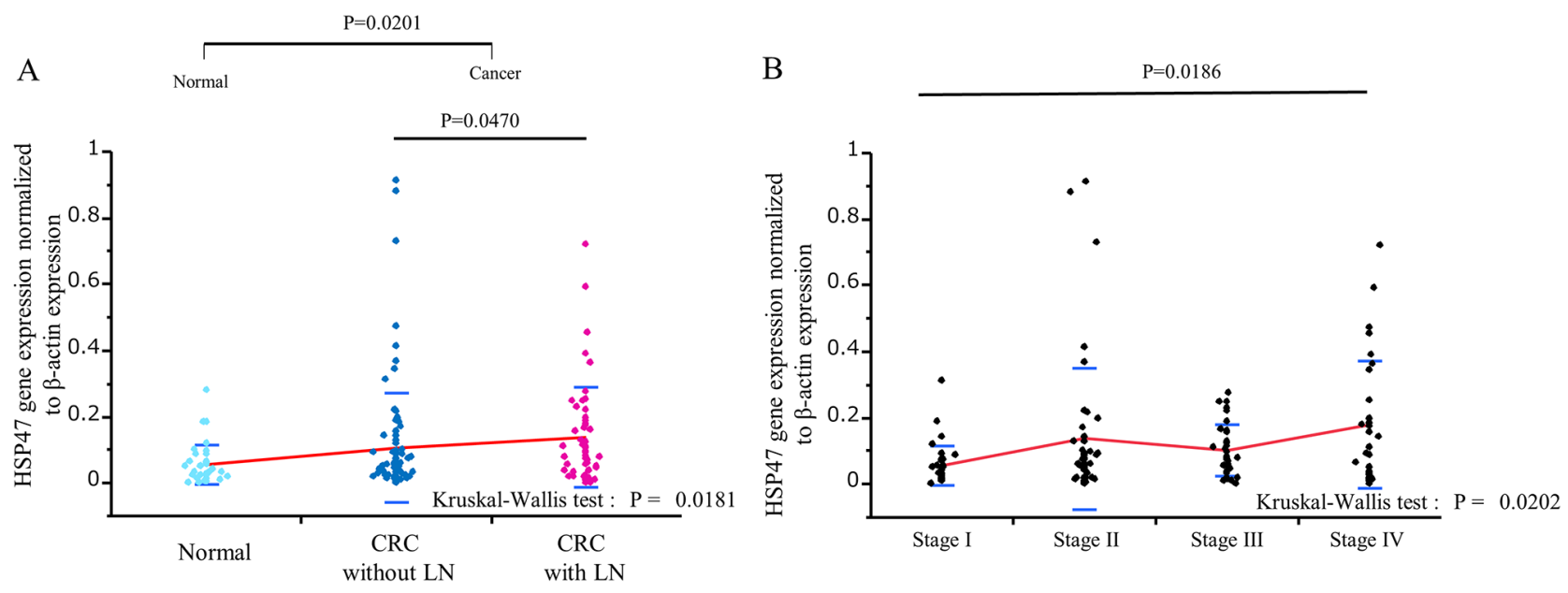

Figure 1. Reverse transcription quantitative PCR analysis of HSP47 gene expression in normal colonic and CRC samples. Data were normalized by $\beta$-actin expression level. Bars represent standard deviations. Statistical analysis was performed using Kruskal-Wallis test and Dunn's test. (A) HSP47 expression level was significantly higher in CRC samples compared with normal samples, and in CRC with LN metastasis compared with CRC without LN metastasis. (B) HSP47 gene expression level in 139 CRC tissues subdivided according to Tumor-Node-Metastasis staging. HSP47, heat shock protein 47; LN, lymph node metastasis; CRC, colorectal cancer.

(70/139) had low expression. Furthermore, high HSP47 expression level was significantly associated with advanced T stage ( $\mathrm{P}=0.0163), \mathrm{LN}$ metastasis $(\mathrm{P}=0.0186)$, venous invasion $(\mathrm{P}=0.0328)$, and advanced TNM stage $(\mathrm{P}=0.0115$; Table $\mathrm{I})$.

Differential gene expression patterns of HSP47 in normal colonic mucosa and CRC tissues. A comparison of HSP47 expression between colon cancer and rectum cancer samples revealed that there was no significant difference in expression between the two cancer types (Fig. S1).

High HSP47 expression level predicts LN metastasis in patients with $C R C$. The present study investigated various factors associated with LN involvement by univariate and multivariate logistic analyses (Table II). Advanced T stage $(\mathrm{P}=0.0007)$, lymphatic invasion $(\mathrm{P}=0.0043)$, venous invasion $(\mathrm{P}=0.0002)$ and high HSP47 expression $(\mathrm{P}=0.0042)$ in $\mathrm{CRC}$ were significantly associated with LN metastasis following univariate analysis. Furthermore, multivariate analysis identified high HSP47 expression [odds ratio (OR): 2.3946, 95\% confidence interval (CI): 1.116397-5.209946; $\mathrm{P}=0.0249$ ] as the only independent predictor of LN metastasis in patients with CRC (Table II).

High HSP47 gene expression affects prognosis in patients with $C R C$. Patients with CRC were divided into two groups according to HSP47 expression level determined by ROC analysis for prognosis (cut-off 0.0924641). Kaplan-Meier analysis indicated that disease-free survival tended to be poorer in the high-expression group, although the difference was not significant (Fig. 2A); however, OS was also significantly poorer in the high-expression group compared with the low-expression group ( $\mathrm{P}=0.0003$, log-rank test; Fig. 2B). Cox's univariate and multivariate analyses of clinicopathological factors related to OS in patients with CRC are presented in Table III. The results from univariate analysis indicated that poor OS was significantly associated with advanced $\mathrm{T}$ stage $(\mathrm{P}<0.0001), \mathrm{LN}$ metastasis $(\mathrm{P}=0.0040)$, hepatic metastasis
$(\mathrm{P}<0.0001)$, distant metastasis $(\mathrm{P}<0.0001)$, lymphatic invasion $(\mathrm{P}=0.0056)$, venous invasion $(\mathrm{P}=0.0051)$ and high HSP47 expression in $\mathrm{CRC}(\mathrm{P}=0.0021)$. In addition, multivariate analysis identified hepatic metastasis [hazard ratio (HR): 9.1250, 95\% CI: 3.7270458-22.288004; P<0.0001] and high HSP47 expression (HR: 2.7407, 95\% CI: 1.1623509-6.1627421; $\mathrm{P}=0.0224)$ as independent prognostic factors in patients with CRC (Table III).

Association between HSP47 expression and LN counts in patients with $C R C$. The association between $\mathrm{LN}$ metastasis status and HSP47 expression level in patients with CRC was evaluated. Patients were classified according to the stage of LN metastasis based on the Japanese Society for Cancer of the Colon and Rectum 7th edition (N0, no metastasis; N1, 1-3 pericolic/perirectal; intermediate LN metastases; $\mathrm{N} 2, \geq 4$ pericolic/perirectal, intermediate LN metastases; N3, main LN metastasis including lateral LN metastasis) (14). Kaplan-Meier analysis demonstrated that patients with N3 had significantly poorer OS than the other groups $(\mathrm{P}<0.0001$; Fig. 3A). HSP47 expression level in N3 patients was significantly higher compared with N0 patients ( $\mathrm{P}=0.0253$; Fig. 3B). ROC curves were also generated to assess the potential significance of HSP47 expression level for the detection of LN metastasis status in patients with CRC. The results demonstrated that HSP47 expression level could discriminate between N1-3 and N0 CRC patients, with an AUC value of 0.60138 (Fig. 3C). In addition, HSP47 level could also discriminate between N2-3 and N0-1 CRC patients, with an AUC of 0.84392 (Fig. 3D).

\section{Discussion}

The present study investigated the gene expression pattern of HSP47 in CRC tissues by RT-qPCR. HSP47 expression level was significantly higher in CRC tissues compared with normal tissue from patients with benign colonic disease and was significantly associated with tumor progression indicated by high $\mathrm{T}$ stage, $\mathrm{LN}$ metastasis and venous invasion and high 
Table I. Association between HSP47 expression level and the clinicopathological characteristics in patients with colorectal cancer.

\begin{tabular}{|c|c|c|c|c|}
\hline \multirow[b]{2}{*}{ Variable } & \multirow[b]{2}{*}{$\mathrm{n}$} & \multicolumn{2}{|c|}{ HSP47 expression } & \multirow[b]{2}{*}{ P-value } \\
\hline & & High $(n=69)$ & Low $(\mathrm{n}=70)$ & \\
\hline Age, years & & & & 0.1072 \\
\hline$<69$ & 70 & 30 & 40 & \\
\hline$\geq 69$ & 69 & 39 & 30 & \\
\hline Sex & & & & 0.4479 \\
\hline Male & 79 & 37 & 42 & \\
\hline Female & 60 & 32 & 28 & \\
\hline Histology & & & & 0.2908 \\
\hline Undifferentiated & 9 & 6 & 3 & \\
\hline Differentiated & 130 & 63 & 67 & \\
\hline Tumor size, mm & & & & 0.1247 \\
\hline$<40$ & 49 & 20 & 29 & \\
\hline$\geq 40$ & 90 & 49 & 41 & \\
\hline $\mathrm{T}$ classification & & & & $0.0163^{\mathrm{a}}$ \\
\hline $\mathrm{T} 1-\mathrm{T} 2$ & 39 & 13 & 26 & \\
\hline T3-T4 & 100 & 56 & 44 & \\
\hline Lymph node metastasis & & & & $0.0186^{\mathrm{a}}$ \\
\hline Present & 88 & 37 & 51 & \\
\hline Absent & 51 & 32 & 19 & \\
\hline Lymphatic invasion & & & & 0.1811 \\
\hline Present & 124 & 64 & 60 & \\
\hline Absent & 15 & 5 & 10 & \\
\hline Venous invasion & & & & $0.0328^{\mathrm{a}}$ \\
\hline Present & 113 & 61 & 52 & \\
\hline Absent & 26 & 8 & 18 & \\
\hline Hepatic metastasis & & & & 0.1376 \\
\hline Present & 20 & 13 & 7 & \\
\hline Absent & 119 & 56 & 63 & \\
\hline Peritoneal metastasis & & & & 0.9918 \\
\hline Present & 2 & 1 & 1 & \\
\hline Absent & 137 & 68 & 69 & \\
\hline Distant metastasis & & & & 0.1041 \\
\hline Present & 16 & 11 & 5 & \\
\hline Absent & 123 & 58 & 65 & \\
\hline Recurrence & & & & 0.1041 \\
\hline Present & 24 & 15 & 9 & \\
\hline Absent & 84 & 38 & 46 & \\
\hline \multicolumn{5}{|l|}{ Stage } \\
\hline I & 33 & 9 & 24 & $0.0115^{\mathrm{a}}$ \\
\hline II & 44 & 21 & 23 & \\
\hline III & 33 & 21 & 12 & \\
\hline IV & 29 & 18 & 11 & \\
\hline
\end{tabular}

(Pearson's $\chi^{2}$ ); ${ }^{a}<0.05$. The cut-off value for high/low HSP47 expression was 0.0969762. HSP47, heat shock protein 47.

TNM stage. High HSP47 expression level also served as a novel predictive biomarker for patients with CRC and LN metastasis, and as an independent prognostic factor in patients with CRC. 
Table II. Univariate and multivariate analyses of associations with lymph node metastasis in patients with colorectal cancer.

\begin{tabular}{|c|c|c|c|c|c|c|}
\hline \multirow[b]{2}{*}{ Variable } & \multicolumn{3}{|c|}{ Univariate analysis } & \multicolumn{3}{|c|}{ Multivariate analysis } \\
\hline & OR & $95 \% \mathrm{CI}$ & P-value & OR & $95 \% \mathrm{CI}$ & P-value \\
\hline Age ( $<69$ vs. $\geq 69$ years) & 1.2321 & $0.617647-2.4697243$ & 0.5534 & - & - & - \\
\hline Sex (female vs. male) & 1.2840 & $0.6395638-2.5783842$ & 0.4810 & - & - & - \\
\hline Tumor size ( $\geq 40$ vs. $<40 \mathrm{~mm}$ ) & 2.0237 & $0.9624956-4.4365109$ & 0.0632 & - & - & - \\
\hline T classification (T3-4 vs. T1-2) & 5.0000 & $1.8374783-12.775448$ & $0.0007^{\mathrm{a}}$ & 2.1400 & $0.7456599-6.9057309$ & 0.1606 \\
\hline $\begin{array}{l}\text { Pathology (poor or mucinous vs. } \\
\text { moderate/well differentiated) }\end{array}$ & 1.4128 & $0.335628-5.5889128$ & 0.6218 & - & - & - \\
\hline $\begin{array}{l}\text { Lymphatic invasion } \\
\text { (present vs. absent) }\end{array}$ & 9.4595 & $1.8123151-174.04766$ & $0.0043^{\mathrm{a}}$ & 1.0124 & $0.0343703-29.441451$ & 0.9935 \\
\hline $\begin{array}{l}\text { Venous invasion } \\
\text { (present vs. absent) }\end{array}$ & 9.1875 & 2.5583968-58.877309 & $0.0002^{\mathrm{a}}$ & 5.2985 & $0.8617945-102.43786$ & 0.0752 \\
\hline $\begin{array}{l}\text { HSP47 gene expression } \\
(\geq 0.0969762 \text { vs. }<0.0969762)\end{array}$ & 2.8846 & $1.3963896-6.0536216$ & $0.0042^{\mathrm{a}}$ & 2.3946 & $1.116397-5.209946$ & $0.0249^{2}$ \\
\hline
\end{tabular}

Logistical regression model; ${ }^{\text {PP }}<0.05$. The cut-off value for high/low HSP47 gene expression was 0.0969762 . OR, odds ratio; CI, confidence interval; HSP47, heat shock protein 47.

A

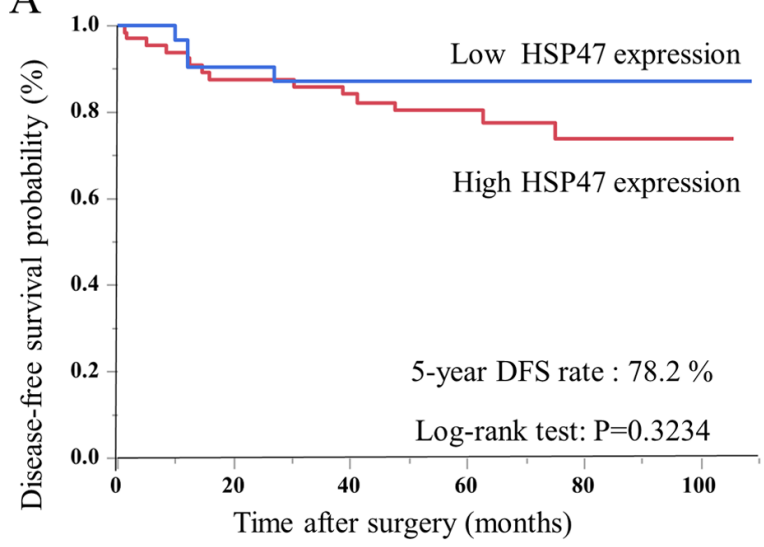

B

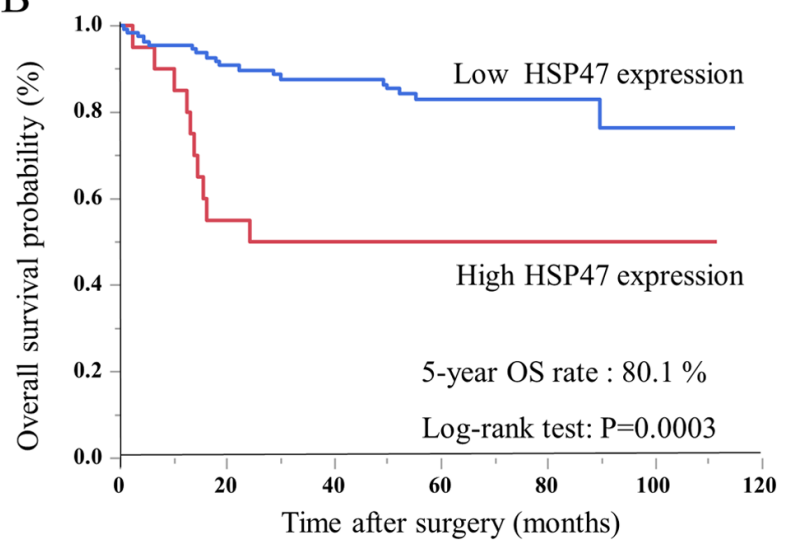

Figure 2. Survival curves of patients with CRC after curative surgery according to HSP47 gene expression status. Kaplan-Meier method was used to determine the cumulative probability of overall survival with Stage I-IV and disease-free survival with Stage I-III patients with CRC, and differences were evaluated using log-rank tests. (A) Disease-free survival. Patients with high HSP47 gene expression levels tended to have poorer disease-free survival than those with low expression levels, although the difference was not significant ( $\mathrm{P}=0.3234$, log-rank test). (B) Overall survival. Patients with high HSP47 gene expression levels had significantly poorer overall survival than those with low expression levels. ( $\mathrm{P}=0.0003, \log$-rank test). CRC, colorectal cancer; HSP47, heat shock protein 47 .

HSP47 is a 47-kDa member of a group of heat shock proteins with unique collagen-specific binding characteristics (15), which was first characterized by Kurkinen et al (16) in murine parietal endoderm cells. Heat shock proteins play an important role as molecular chaperones in protein folding, by assembling newly synthesized proteins or reassembling misfolded proteins (17). HSP47 binds to nascent single polypeptide chains of procollagen immediately after entry into the endoplasmic reticulum and dissociates from procollagen chains in the Golgi apparatus (18). When aberrant procollagen accumulates in the endoplasmic reticulum due to heat shock, depletion of ascorbic acid or after treatment with $\alpha, \alpha^{\prime}$-dipyridyl, which inhibits procollagen secretion and causes accumulation of procollagen in the endoplasmic reticulum (19). Some studies have suggested that procollagen gene expression level and rates of procollagen synthesis were regulated with HSP47 (20), and that HSP47 expression was increased in fibrotic human lung, kidney and skin (21-24).

HSP47 has been mapped to human chromosome 11q13.5, which is a known 'hot spot' in a number of human cancers (25). Interestingly, altered HSP47 expression has been identified in several cancers, including sarcoma, esophageal squamous cell carcinoma and ulcerative colitis-associated carcinoma (26-28). Maitra et al (29) reported HSP47 immunolabeling in the tumor-associated stroma and suggested that it may act as a novel diagnostic and therapeutic marker in pancreatic carcinoma. Furthermore, we previously reported that the number of HSP47-positive spindle-shaped stroma cells in the cancer stroma of patients with CRC could serve as a novel predictive biomarker of LN metastasis, early recurrence and poor prognosis (8). In addition, HSP47 silencing has been shown 
Table III. Univariate and multivariate analyses of associations with overall survival in patients with colorectal cancer.

\begin{tabular}{|c|c|c|c|c|c|c|}
\hline \multirow{2}{*}{$\frac{\text { (Cohort 1: Protein analysis) }}{\text { Variables }}$} & \multicolumn{3}{|c|}{ Univariate analysis } & \multicolumn{3}{|c|}{ Multivariate analysis } \\
\hline & HR & $95 \% \mathrm{CI}$ & P-value & HR & $95 \% \mathrm{CI}$ & P-value \\
\hline Age ( $<69$ vs. $\geq 69$ years) & 1.7043 & $0.8012998-3.8397503$ & 0.1682 & - & - & - \\
\hline Sex (male vs. female) & 1.3229 & $0.6220246-2.9802979$ & 0.4731 & - & - & - \\
\hline Tumor size ( $\geq 40$ vs. $<40 \mathrm{~mm}$ ) & 1.8287 & $0.8144726-4.6473787$ & 0.1486 & - & - & - \\
\hline T classification (T3-4 vs. T1-2) & 13.3454 & 2.8403789-238.09155 & $<0.0001$ & 3.8129 & $0.733633-70.061812$ & 0.1260 \\
\hline Lymph node metastasis & 3.0116 & $1.4279703-6.5249787$ & $0.0040^{\mathrm{a}}$ & 1.3758 & $0.5677664-3.3313589$ & 0.4761 \\
\hline Peritoneal metastasis & 6.5208 & $0.3625655-31.578247$ & 0.1555 & - & - & - \\
\hline Hepatic metastasis & 16.5158 & 7.466573-36.758521 & $<0.0001$ & 9.1250 & $3.7270458-22.288004$ & $<0.0001$ \\
\hline Distant metastasis & 7.2862 & $3.2929176-15.473565$ & $<0.0001$ & 2.0538 & $0.7842089-5.1884429$ & 0.1403 \\
\hline $\begin{array}{l}\text { Pathology (poor or mucinous vs. } \\
\text { moderate/well differentiated) }\end{array}$ & 1.6081 & $0.3825837-4.5888813$ & 0.4652 & - & - & - \\
\hline $\begin{array}{l}\text { Lymphatic invasion) } \\
\text { (present vs. absent }\end{array}$ & 1.6488 & $0.4826371-2.07195$ & $0.0056^{\mathrm{a}}$ & 2.1415 & $0.0606119-16.498407$ & 0.4061 \\
\hline $\begin{array}{l}\text { Venous invasion } \\
\text { (present vs. absent) }\end{array}$ & 7.6486 & $1.628946-136.4308$ & $0.0051^{\mathrm{a}}$ & 1.3460 & $0.2462182-25.080995$ & 0.7719 \\
\hline $\begin{array}{l}\text { HSP47 gene expression } \\
(\geq 0.0924641 \text { vs. }<0.0924641)\end{array}$ & 3.7958 & $1.6753552-8.1191931$ & $0.0021^{\mathrm{a}}$ & 2.7407 & $1.1623509-6.1627421$ & $0.0224^{\mathrm{a}}$ \\
\hline
\end{tabular}

Cox proportion hazard regression model; ${ }^{\mathrm{a}} \mathrm{P}<0.05$. CI, confidence interval. The cut-off value for high/low HSP47 gene expression was 0.0924641 ; HSP47, heat shock protein 47 .

A

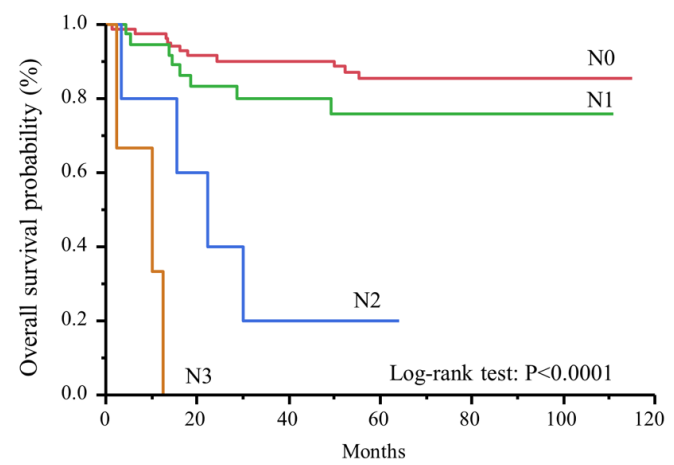

C

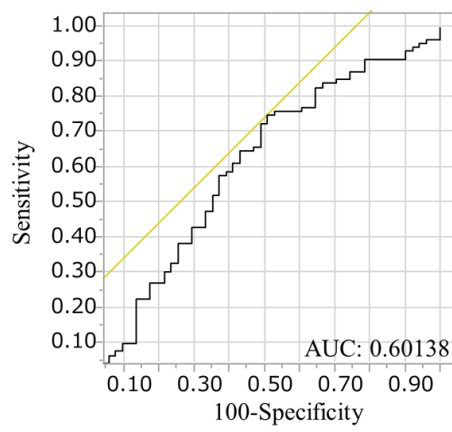

B

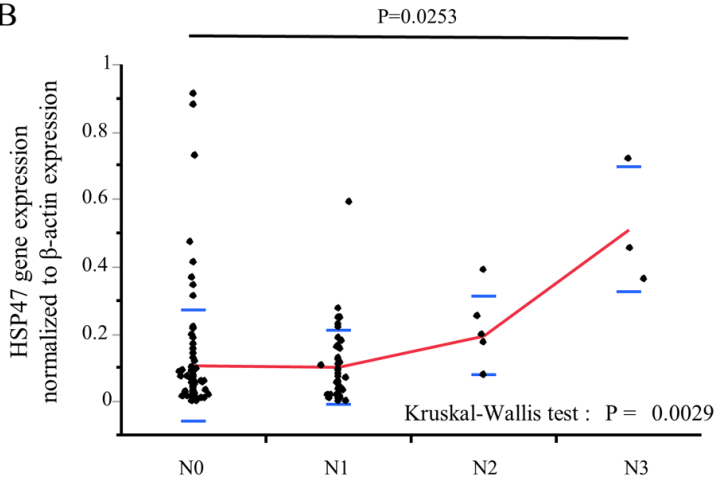

Classification of $\mathrm{LN}$

N: 0

$\mathrm{N}: 1-3$

$\mathrm{N}: \geq 4$

Main LN metastasis (including lateral LN)
D

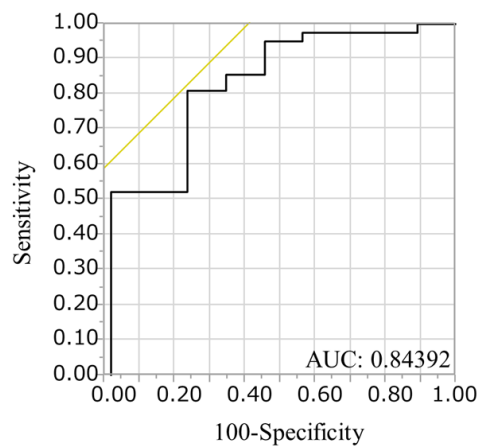

Figure 3. Association between HSP47 expression level and N stage. (A) Survival curves for patients with CRC after curative surgery according to N stage. Patients with high $\mathrm{N}$ stage had poorer OS than those with low $\mathrm{N}$ stage ( $\mathrm{P}<0.0001, \log$-rank test). (B) HSP47 gene expression levels in 139 patients with $\mathrm{CRC}$ subdivided by N stage. HSP47 gene expression level was significantly higher in N3 compared with N0 patients with CRC. (C) ROC curve analysis using HSP47 expression level to distinguish between CRC with and without LN metastasis (N0 vs. N1-3). HSP47 expression level yielded an AUC value of 0.60138 for detecting CRC with LN metastasis. (D) ROC curve analysis using HSP47 expression level to detect CRC with severe LN metastasis (N0-1 vs. N2-3). HSP47 expression level yielded an AUC value of 0.84392 for discriminating between N2-3 CRC and N0-1 CRC. AUC, area under the curve; CRC, colorectal cancer; HSP47, heat shock protein 47; ROC, receiver operating characteristic. 
to inhibit cell proliferation, migration and invasion in cervical squamous cell carcinoma (30).

Regarding HSP47 gene expression, Morino et al (31) demonstrated that tumor cell lines derived from metastatic carcinomas that remained metastatic in animals can synthesize higher levels of HSP47. Naitoh et al (24) also reported that HSP47 expression level was upregulated by 8-fold in keloid lesions. However, the association between HSP47 expression level and tumor progression, prognosis and metastasis in cancer patients remains unclear. To the best of our knowledge, the present study was the first to suggest that high HSP47 expression level in CRC primary tumors may be considered as an independent marker for the prediction of LN metastasis and poor prognosis in patients with CRC.

Neoadjuvant chemotherapy or chemoradiotherapy are currently used as treatments for patients with advanced rectal cancer and have been shown to decrease local recurrence and increase survival (32). Correct preoperative staging plays therefore a critical role in determining whether patients with rectal cancer should undergo neoadjuvant therapy. Similarly, preoperative neoadjuvant treatments and decisions regarding the range of LN dissection depend on accurate LN staging in patients with colon cancer (33). In the present study, HSP47 expression value in the group with LN was significantly higher than in the group without LN $(0.137848 \pm 0.149551$ vs. $0.106957 \pm 0.166488)$. In addition, patients with N2 or N3 tumors had significantly poorer OS than other patients, and HSP47 gene expression level was also significantly higher in N2 and N3 patients compared with N0 and N1 patients. This was supported by markedly higher AUC values for comparisons between N2-3 and N0-1 CRC patients (AUC $=0.84392$ ). Furthermore, HSP47 expression was identified as the only independent predictive factor for $\mathrm{LN}$ metastasis in patients with CRC. Evaluation of HSP47 expression level may therefore help deciding the appropriate neoadjuvant chemotherapy to be used, and determining the extent of LN dissection (local or wide excision). HSP47 expression level may therefore help decreasing the size of surgery and evaluate the requirement of neoadjuvant chemotherapy in patients with CRC before surgery.

Previously, we demonstrated that the number of HSP47-positive spindle cells in the stroma of CRC may serve as a novel predictive biomarker of LN metastasis, early recurrence and poor prognosis via immunostaining (12). In the present study, we used mRNA to examine LN metastasis and prognostic factors of CRC patients. Although it is easy to evaluate the prognostic factor of CRC using protein staining, the objectivity can be poor and the evaluation can be dependent of the observer. Evaluating mRNA expression may be a more useful method because it allows quantification, reducing human bias and leading therefore to a more accurate evaluation of LN metastasis and prognosis in patients with CRC. Although HSP47 expression level was quantified in frozen surgical specimens rather than in preoperative biopsy samples, the results from the present study suggested that evaluation of HSP47 expression level in biopsy samples may represent a promising clinical tool for the preoperative prediction of LN metastasis, allowing therefore the determination of appropriate treatment strategies in patients with CRC. It may be worth mentioning that the current study did not actually use preoperative biopsies, although it aimed to determine if it could be possible to determine the $\mathrm{LN}$ metastasis in patients with CRC.

In summary, the results from the present study indicated that HSP47 expression level in CRC tissues may be considered as a potential biomarker for predicting $\mathrm{LN}$ metastasis status and prognosis in patients with CRC. These results suggested that assessing LN metastasis may lead to a reduction in surgery in CRC and may help deciding about preoperative chemotherapy in rectal cancer. By examining the OS via evaluation of HSP47 expression, it may be possible to predict before surgery that postoperative chemotherapy may be required for patients with both colon and rectal cancers.

\section{Acknowledgements}

Not applicable.

\section{Funding}

This study was supported in part by a Grant in Aid for Scientific Research (grant no. 21791280) from the Ministry of Education, Culture, Sports, Science and Technology, Japan.

\section{Availability of data and materials}

The datasets used and/or analyzed during the present study are available from the corresponding author on reasonable request.

\section{Authors' contributions}

KM, YT, MaK and YO designed the study. TI, YN, SO, TS, HF, JH, MiK, TA, YI and YM performed the experiments. KM, YT and $\mathrm{YO}$ acquired, analyzed and interpreted data. KM and YT drafted the manuscript. MaK supervised and coordinated the study. All the authors were involved in writing the manuscript. All authors have read and approved the final manuscript.

\section{Ethics approval and consent to participate}

The research protocol was approved by Mie University Hospital (Mie, Japan) Ethical Review Committee (approval no. 2632). All participants provided written informed consent and agreed to donate their clinical specimens for research purposes.

\section{Patient consent for publication}

Not applicable.

\section{Competing interests}

The authors declare that they have no competing interests.

\section{References}

1. Jemal A, Bray F, Center MM, Ferlay J, Ward E and Forman D: Global cancer statistics. CA Cancer J Clin 61: 69-90, 2011.

2. Edge S, Compton C, Fritz A, Greene F and Trotti A (eds): AJCC Cancer Staging Manual. 7th edition. Springer, New York, NY, pp237-46, 2010. 
3. Chau I and Cunningham D: Adjuvant therapy in colon cancer: Current status and future directions. Cancer Treat Rev 28 223-236, 2002.

4. Schrag D, Gelfand SE, Bach PB, Guillem J, Minsky BD and Begg CB: Who gets adjuvant treatment for stage II and III rectal cancer? Insight from surveillance, epidemiology, and end results-Medicare. J Clin Oncol 19: 3712-3718, 2001.

5. Siegel R, Naishadham D and Jemal A: Cancer statistics, 2012. CA Cancer J Clin 62: 10-29, 2012.

6. Kwak JY, Kim JS, Kim HJ, Ha HK, Yu CS and Kim JC: Diagnostic value of FDG-PET/CT for lymph node metastasis of colorectal cancer. World J Surg 36: 1898-1905, 2012.

7. Low G, Tho LM, Leen E, Wiebe E, Kakumanu S, McDonald AC and Poon FW: The role of imaging in the pre-operative staging and post-operative follow-up of rectal cancer. Surgeon 6 : 222-231, 2008

8. Imaoka H, Toiyama Y, Saigusa S, Kawamura M, Kawamoto A, Okugawa Y, Hiro J, Tanaka K, Inoue Y, Mohri Y and Kusunoki M: RacGAP1 expression, increasing tumor malignant potential, as a predictive biomarker for lymph node metastasis and poor prognosis in colorectal cancer. Carcinogenesis 36: 346-354, 2015.

9. Imaoka H, Toiyama Y, Fujikawa H, Hiro J, Saigusa S, Tanaka K, Inoue Y, Mohri Y, Mori T, Kato T, et al: Circulating microRNA-1290 as a novel diagnostic and prognostic biomarker in human colorectal cancer. Ann Oncol 27: 1879-1886, 2016.

10. Lina O, Marie-Louise H, Anne I, Gudrun L and Sten H: Allocating colorectal cancer patients to different risk categories by using a five-biomarker mRNA combination in lymph node analysis. PLoS One 15: e0229007, 2020.

11. Li H, Ma SQ, Huang J, Chen XP and Zhou HH: Roles of long noncoding RNAs in colorectal cancer metastasis. Oncotarget 8 : 39859-39876, 2017.

12. Mori K, Toiyama Y, Otake K, Fujikawa H, Saigusa S, Hiro J, Kobayashi M, Ohi M, Tanaka K, Inoue Y, et al: Proteomics analysis of differential protein expression identifies heat shock protein 47 as a predictive marker for lymph node metastasis in patients with colorectal cancer. Int J Cancer 140: 1425-1435, 2017

13. Livak KJ and Schmittgen TD: Analysis of relative gene expression data using real-time quantitative PCR and the 2(-Delta Delta C(T)) method. Methods 25: 402-408, 2001.

14. Japanese Society for Cancer of the Colon and Rectum General Rules for Clinical and Pathological Studies on Cancer of the Colon RaARV. 7th edition (in Japanese). Tokyo, pp36-37, 2009.

15. Nagata K, Saga S and Yamada KM: A major collagen-binding protein of chick embryo fibroblasts is a novel heat shock protein. J Cell Biol 103: 223-229, 1986.

16. Kurkinen M, Taylor A, Garrels JI and Hogan BL: Cell surface-associated proteins which bind native type IV collagen or gelatin. J Biol Chem 259: 5915-5922, 1984.

17. Schlesinger MJ: Heat shock proteins. J Biol Chem 265 12111-12114, 1990.

18. Satoh M, Hirayoshi K, Yokota S, Hosokawa N and Nagata K: Intracellular interaction of collagen-specific stress protein HSP47 with newly synthesized procollagen. J Cell Biol 133: 469-483, 1996

19. Nakai A, Satoh M, Hirayoshi K and Nagata K: Involvement of the stress protein HSP47 in procollagen processing in the endoplasmic reticulum. J Cell Biol 117: 903-914, 1992.
20. Kawada N, Kuroki T, Kobayashi K, Inoue M, Nakatani K, Kaneda $\mathrm{K}$ and Nagata K: Expression of heat-shock protein 47 in mouse liver. Cell Tissue Res 284: 341-346, 1996.

21. Razzaque MS, Nazneen A and Taguchi T: Immunolocalization of collagen and collagen-binding heat shock protein 47 in fibrotic lung diseases. Mod Pathol 11: 1183-1188, 1998.

22. Razzaque MS, Kumatori A, Harada $\mathrm{T}$ and Taguchi $\mathrm{T}$ : Coexpression of collagens and collagen-binding heat shock protein 47 in human diabetic nephropathy and IgA nephropathy. Nephron 80: 434-443, 1998.

23. Kuroda K, Tsukifuji R and Shinkai H: Increased expression of heat-shock protein 47 is associated with overproduction of type I procollagen in systemic sclerosis skin fibroblasts. J Invest Dermatol 111: 1023-1028, 1998.

24. Naitoh M, Hosokawa N, Kubota H, Tanaka T, Shirane H, Sawada M, Nishimura Y and Nagata K: Upregulation of HSP47 and collagen type III in the dermal fibrotic disease, keloid. Biochem Biophys Res Commun 280: 1316-1322, 2001.

25. Sauk JJ, Nikitakis N and Siavash H: Hsp47 a novel collagen binding serpin chaperone, autoantigen and therapeutic target. Front Biosci 10: 107-118, 2005.

26. Morino M, Tsuzuki T, Iijima H, Shirakami T, Kiyosuke YI, Ishikawa Y, Yoshimura M and Yoshikumi C: Marked induction of HSP47, a collagen-binding stress protein, during solid tumor formation of ascitic Sarcoma 180 in vivo. In Vivo 9: 503-508, 1995.

27. Lee HW, Kwon J, Kang MC, Noh MK, Koh JS, Kim JH and Park JH: Overexpression of HSP47 in esophageal squamous cell carcinoma: Clinical implications and functional analysis. Dis Esophagus 29: 848-855, 2016.

28. Araki K, Mikami T, Yoshida T, Kikuchi M, Sato Y, Oh-ishi M, Kodera Y, Maeda T and Okayasu I: High expression of HSP47 in ulcerative colitis-associated carcinomas: Proteomic approach. $\mathrm{Br}$ J Cancer 101: 492-497, 2009.

29. Maitra A, Iacobuzio-Donahue C, Rahman A, Sohn TA, Argani P, Meyer R, Yeo CJ, Cameron JL, Goggins M, Kern SE, et al: Immunohistochemical validation of a novel epithelial and a novel stromal marker of pancreatic ductal adenocarcinoma identified by global expression microarrays: Sea urchin fascin homolog and heat shock protein 47. Am J Clin Pathol 118: 52-59, 2002.

30. Yamamoto N, Kinoshita T, Nohata N, Yoshino H, Itesako T, Fujimura L,Mitsuhashi A,Usui H,Enokida H,Nakagawa M, et al: Tumor-suppressive microRNA-29a inhibits cancer cell migration and invasion via targeting HSP47 in cervical squamous cell carcinoma. Int J Oncol 43: 1855-1863, 2013.

31. Morino M, Tsuzuki T, Ishikawa Y, Shirakami T, Yoshimura M, Kiyosuke Y, Matsunaga K, Yoshikumi C and Saijo N: Specific expression of HSP47 in human tumor cell lines in vitro. In Vivo 11: 17-21, 1997.

32. Krishnamurthi SS, Seo Y and Kinsella TJ: Adjuvant therapy for rectal cancer. Clin Colon Rectal Surg 20: 167-181, 2007.

33. Greene FL PD, Fleming I and Fritz A (eds): AJCC Cancer Staging Manual. 6th edition. Springer-Verlag, Berlin, 2002.

This work is licensed under a Creative Commons

Attribution-NonCommercial-NoDerivatives 4.0 International (CC BY-NC-ND 4.0) License. 